\title{
Shanghai takes steps to boost scientific skills
}

Beijing. The city of Shanghai has taken a series of independent initiatives aimed at securing its primacy as a centre for Chinese science and technology. But its actions have also raised fears of growing regional imbalance of research funding in China.

The city has just held a major, biennial science and technology fair, and has set up its own centre for human genome research. Shanghai has also announced the doubling of a loan scheme to support basic research in the city, a training scheme for young scientists and special bonuses for outstanding young researchers.

The two-week fair, which opened on 18 October, was held for the first time in 1991, and will now take place every two years. Its purpose was to bring home to every citizen of the city the importance of science and technology, and it featured exhibitions, academic symposia and various popular science activities. During the fair, all of the city's major higher and research institutions were open to the public, with scientists standing by to explain their work.

The proposed Shanghai Key Laboratory for Human Genome Research received approval from the Shanghai Commission of Science and Technology on 1 October. The creation of the laboratory may have important repercussions for the management of research in a country which is just beginning to break away from the usual strict central control over scientific institutions.

In particular, although the Shanghai facility was launched just after China had announced a national human genome project (see Nature 365, 200; 1993), it remains very much Shanghai's own initiative, and its research plan, funding and management will not be affected by the national initiative.

The extra money for researchers in the city will come from the expansion of a agreement signed in 1991 by the Shanghai Commission of Science and Technology and the Shanghai Industrial and Commercial Bank. The bank has established a loan fund that has channelled nearly 40 million Yuan for 1991-93 to support research. On 15 October, the two sides agreed to provide an additional 60 million Yuan to the fund in the next two years (1993-95).

Science administrators will try to use the money to strengthen areas of research where Shanghai is already strong. Biological, materials and information sciences are three areas earmarked for additional funding; a total of 14 projects in those fields have been selected for priority support, each receiving 300,000 Yuan.

The commission has also launched a three-tier young scientist training scheme, aimed at 'general' young scientists, 'key' young scientists and 'principal' young scientists, who will get different levels of financial support.

With backing from the municipal bureaus of finance and personnel, the city will select a hundred young scientists each year

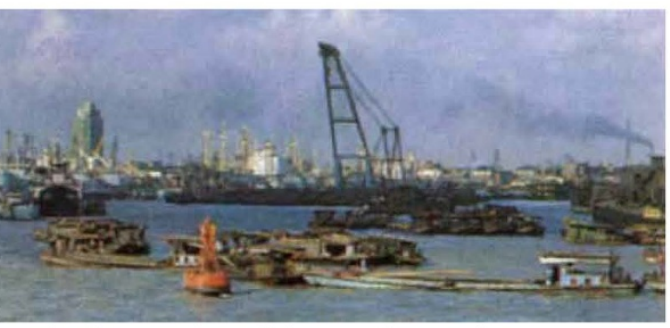

busy harbour - busy laboratories too?

to receive a special monthly bonus ranging from 300 to 400 Yuan - higher than the monthly salary of most Chinese scientists.

Those who have worked with projects

\section{Genetic testing under scrutiny in US}

Washington. Existing policy guidelines governing the use of genetic testing need an urgent overhaul in order to stress the importance of voluntary participation, informed consent and the need to protect confidentiality, according to a report released last week by a committee of the Institute of Medicine of the National Academy.

In its two-volume report, Assessing $\mathrm{Ge}$ netic Risks: Implications for Health and Social Policy, the committee identified a number of pressing concerns and outlined its recommendations, including the need for greater federal supervision of genetic testing laboratories, and improved quality control of genetic tests.

The committee also called for safeguards to protect individuals against discrimination from health insurers and employers, and advocated more rigorous education and training of health care providers in the area of genetic testing and counselling.

The majority of committee members agreed that there was a need for a broadly representative and independent national advisory committee that would report to the Secretary of the Department of Health and Human Services and to Congress.

The basic message of the report, according to Neil A. Holtzman, professor of paediatrics, health policy and management and epidemiology at Johns Hopkins University Hospital, is that "the committee places patient autonomy above all else".

According to the committee, prenatal testing raises some of the most difficult issues: the ability of physicians to diagnose genetic disorders of the fetus far exceeds any ability to cure them; a woman's reproductive choices are more limited at this funded by the National Science Foundation of China and by the Shanghai Science Foundation are eligible for consideration. The aim is to counteract the attraction of commercial jobs, which are thought to be taking some of the best basic researchers away from science.

And Shanghai has painstakingly attempted to create a favourable infrastructure for research in the city. Its Pudong District has given priority to high technology, and has become a key growth area for Shanghai's industry. The new development zone is the home of a national Chinese high technology corporation, a conglomerate involving the country's 609 principal universities. The city's technology exports now go to more than 30 foreign countries, making an annual profit of $\$ 250$ million.

You Qin Li results can have serious implications.

For these reasons, the committee felt that women undergoing prenatal testing should be fully informed about the benefits and risks of the testing procedure, the possible outcomes, and the available options.

All counselling, which should be given before and after testing, should be of a "nondirective" nature; decisions about whether or not to continue with a pregnancy should be left to the individual.

The committee strongly opposes the use of prenatal testing for the pursuit of eugenic goals, such as determining the sex or other non-disease oriented traits of the fetus. And although the committee recommended that all screening - including that of newborns - should be voluntary it did feel that, following the careful evaluation of pilot studies, state health departments could mandate the "offering" of tests for diagnosing treatable conditions in newborns.

Where newborns being tested for disorders would clearly benefit from early diagnosis and treatment (for example, in the metabolic disorders phenylketonuria and congenital hypothyroidism), some committee members felt that a case could be made for mandating genetic testing.

The committee urged caution over the use of genetic tests to determine a person's susceptibility or predisposition to genetic disorders that can occur later in adult life. For single-gene disorders, the committee said that population screening should be restricted to conditions of a relatively high frequency and that are either be preventable or treatable.

Diane Gershon stage, and the occurrence of false-positive 